\title{
São Bento
}

\section{e a ordo monachorum (1136-1202)}

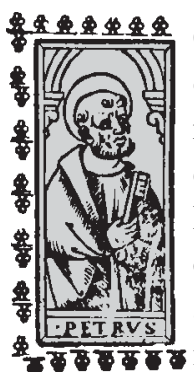
Com a comemoração de 1.500 anos do nascimento do fundador do monaquismo ocidental nos ocorre examinar qual o papel que desempenhou a visão teológica e religiosa do "profeta calabrês", o abade Joaquim de Fiore, que marcou tão profundamente o seu tempo, bem como os séculos que se seguiram.

É uma idéia aceita entre os estudiosos do pensamento medieval que a interpretação da história de Joaquim de Fiore nasce de uma exegética das Escrituras Sagradas a qual, em resumo, leva a uma aplicação do método à história da humanidade. $\mathrm{O}$ original do controvertido abade, em boa parte é fruto de seu espírito e intelecto, servindo na época de fértil incubadora para novas interpretações e de fonte inspiradora às heresias que não deixaram de ser combatidas oficialmente pela instituição eclesiástica medieval.

Em várias de suas obras, no Liber Concordiae Novi ac Veteris Testamenti (1), no Expositio in Apocalypsim (2), no Psalterium decem chordarum (3) e ainda no Tractatus super Quatuor Evangelia (4), encontramos o desenvolvimento de suas idéias e concepções em que o surgimento de São Bento e sua Ordem é assinalado como fato precursor da terceira idade na sucessão dos tempos.

A importância teológica da doutrina trinitária na obra de Joaquim nos permite avaliar o seu papel na formação de sua concepção de história. A Trindade se manifesta na história da humanidade determinando suas etapas e permitindo uma interpretação. Mais do que isso, a Trindade serve de esquema para reconhecer uma escala de valores éticos no comportamento da humanidade, no roteiro de sua salvação. É sob o mistério da Trindade que Joaquim constrói a periodização que representa as três idades do mundo (status mundi). O período do Pai, no qual os homens viviam segundo a carne (in quo vivebant homines secundum carnem), predomina a Lei e é a época dos desposados e laicos. É o período em que predomina o Velho Testamento. A este se sucede o período do Filho, o período da Graça, no qual os homens vivem num estádio intermediário entre o espírito e a carne (in quo vivitur inter utrunque, hoc est intec
NACHMAN FALBEL é professor de História Medieval da USP e autor de Os Espirituais

Franciscanos

(Perspectiva).

\footnotetext{
1 Liber Concordiae Novi ac Veteris Testamenti, Veneza, 1519 (reprod. Graz).

2 Expositio in Apocalypsim Veneza, 1527 (reprod. Graz).

3 Psalterium decem chordarum, Veneza, 1527 (reprod. - Graz).

4 Tractatus super Quatuor Evangelia, ed. E. Buo-
} naiuti, Roma, 1930. 
5 Conc. lib. II, Tract. 2, cap. 4.

6 Largamente empregado por Joaquim em todos os seus escritos.

7 Conc. lib. II, Tract. 1, cap. 2

8 Desenvolvi estes aspectos decorrentes das doutrina do mistico calabres em

minha tese de doutorad

A Luta dos Espirituais na

Ordem Franciscana e su

Contribuição para Reformulação da Doutrina do Poder Papal, FFLCH
USP, 1972 (reed. São PauUSP, 1972 (reed. São Pa
lo, Perspectiva, 1995).

9 Conc. lib. II, Tract. 1, cap. 8.

10 Idem, cap. 9 carnem et espiritum). Este período é a época dos clérigos e nele predomina o Novo Testamento. O terceiro período é o do Espírito Santo, o período do Amor, onde predominará o espírito (in quo vivitur secundum espiritum), caracterizado pelo Evangelho do Espírito Santo ou o Evangelho Eterno (evangelium aeternum), que significa um conhecimento espiritual superior dos dois Testamentos (o Velho e o Novo). Esse espírito eterno sacado das Escrituras pelo spiritualis intelectus, por uma interpretação espiritual superior, é o que subsistirá enquanto a letra escrita desaparecerá no futuro. Essa intelligentia spiritualis será comunicada aos viri spiritualis, fundamento da nova Igreja Espiritual (Ecclesia spiritualis) assentada sobre uma nova ordem monástica (ordo iustorum; ordo monachorum), tomando o lugar da Igreja carnal, hierarquizada e predominante até o seu tempo.

Partindo de um cômputo sui generis, ele estabelece um triplo ciclo de 42 gerações. $\mathrm{O}$ primeiro período vai de Adão a Cristo; o segundo de Cristo até o ano de 1260; e o terceiro de 1260 em diante. Cada período ou idade possui um precursor e um iniciador. Cada período, que tem a duração de 42 gerações (segundo Mt. 1, 17), é equivalente a 3 x 14 gerações, ou seja, de Abraão a Davi, de Davi até o cativeiro da Babilônia, do cativeiro até Cristo. Cada geração possui trinta anos, e assim sendo temos 30 x 42 gerações, que é igual a 1.260, isto é, o ano de início da terceira idade, que teve como precursor São Bento e terminará somente com o Juízo Final. O rei Ozias é o precursor do segundo período que se iniciou com Zacarias, o pai de João Batista.

O modelo desta concepção de história encontra-se, em parte, na própria historiografia medieval, a começar com Santo Agostinho. Mas enquanto a historiografia medieval em sua generalidade encerra o seu ciclo com a sexta idade, aetas sexta, como sendo a era da Encarnação e toda a história anterior da humanidade é uma preparação até se chegar a esta etapa, em Joaquim se dá uma ruptura que ultrapassa o marco da idade do Filho para dar um significado histórico ao Espírito Santo. Este deverá ter também a sua realização histórica, e para Joaquim elaé mais importante pois inau- gurará a humanidade do futuro. Seja qual for a fonte que o inspirou, bizantina ou cisterciense, o que há de marcante em sua concepção é justamente o papel atribuído ao Espírito Santo na economia religiosa, e é esse período que "electus est ad libertatem contemplationis scriptura attestante qui ait: Ubi spiritus ibi libertas" (5).

Por outro lado, o seu método é o da "concordância" entre o Velho e o Novo Testamento, "secundum coaptationem concordiae" (6), que é algo diferente do método alegórico tradicional. O princípio hermenêutico é o do "misticus intellectus qui sicut dicut est a duobus procedit" (7). Este princípio é que permite a "concórdia" das duas histórias, isto é, do Velho Testamento e do Novo Testamento. Mas tal "concórdia" está intimamente associada ao mistério da Santíssima Trindade e à inter-relação existente entre as pessoas que a compõem.

O gênero da exegese profética de Joaquim está ligado diretamente à interpretação do livro do Apocalipse, dedicando-se o abade a revelar o significado hermético e simbólico dessa fonte importante para a gênese da mística medieval. O Expositio in Apocalypsim criará uma verdadeira escola de interpretação joaquimita que terá acolhida nos círculos "espirituais" da ordem franciscana, mas não deixará de ter sua influência também em outros lugares (8).

Joaquim de Fiore ao falar da ordo monachorum ou do terceiro período, o do Espírito Santo, vê nele dois precursores em que Eliseu representa a initiatio prima enquanto que São Bento representou a initiatio secunda, conforme ele mesmo diz na Concordia (9): "Igitur primus ordo iniciatus est ab Adam: secundus ab Ozia rege Iuda: Tertius secundum aliquid ab Helyseo profeta: secundum aliquid a beato Benedicto". E em outro lugar da mesma obra ele reafirma a mesma periodização histórica: "Quia igitur persone deitatis tres sunt coeterne sibi et coequales secundum hoc quod pertinet ad similitudinem ipsarum personarum primus status tenerdus est ab Adam usque ad Christum: secundus ab Ocia rege usque ad presens: Tertius a beato Benedicto usque ad consumationem seculi" (10). 
Entre os escritos genuínos de Joaquim de Fiore encontra-se uma obra que aparece nos manuscritos mais antigos do abade calabrês em particular da Biblioteca Antoniana de Pádua (Ms. 322, ff. 141-9) da primeira metade do século XIII, que teve por título o nome de Tractatus de Vita S. Benedicti et de officio Divino secundum eius doctrinam (11). Tratase de uma biografia de São Bento e uma interpretação da sua Regra tendo como base o método da "concórdia" entre o Velho e o Novo Testamento. Na verdade, nesta obra, Joaquim de Fiore, utilizando-se de um símbolo místico referente ao número 12 e sua divisão em 5 e 7, tenta enfatizar o papel da ordem beneditina e a cisterciense em sua versão da história da humanidade, vindo acentuar a importância que São Bento assume na sua visão cósmica.

Entre os muitos seguidores das doutrinas de Joaquim de Fiore na ordem franciscana encontramos Bartolomeu de Pisa, que escreve, em 1385, o Liber de Conformitate Vitae Beati Francisci ad Vitam Domini Iesu (12), em que se remonta à idéia joaquimita dos sete selos ou idades à luz do Velho e do Novo Testamento, chegando à conclusão de que São Francisco é o anjo do sexto selo do Novo Testamento. Para ele o quinto selo ou idade é o das invasões bárbaras, cuja figura central é a de São Bento, assim como o selo seguinte é o de Frederico II, sendo sua figura central São Francisco. Na literatura herética posterior, também seguindo as pegadas de Joaquim de Fiore, mas transformando-as radicalmente, São Bento será visto como um dos Sete Anjos e uma das Sete Igrejas, tal como ocorre na doutrina do famoso heresiarca Dolcino de Novara que difundiu suas concepções pelo ano de 1300 (13).

Para Dolcino, que parte de uma interpretação próxima à dos joaquimitas mais exaltados, ainda que com alguma derivação particular, existem quatro status, sendo que o primeiro pertence aos patriarcas, profetas e outros homens justos do Velho Testamento e que viviam em perfeita situação de matrimônio antes de Cristo, quando o estado espiritual do homem se afastou da virtude. O segundo status, que teve início com Cristo e seus apóstolos, proveu o remédio perfeito para os males do período precedente e trouxe vida a um novo plano espiritual, sobrepondo a castidade ao matrimônio e a pobreza à riqueza. Esse período perdurou até a época do Papa Silvestre e do Imperador Constantino, mas começou a declinar a partir desse tempo. $\mathrm{O}$ terceiro período, que se iniciou com o Papa Silvestre, assistiu à conversão em massa dos povos gentios, e ao mesmo tempo que os papas acumulavam riquezas e possessões, o amor novamente esfriava de modo que um modo mais perfeito de vida novamente teve início com São Bento e finalmente com São Francisco e São Domingos. Mas agora (no tempo de Dolcino) os prelados, o clero e os religiosos tornaram-se indiferentes ao amor a Deus e ao seu semelhante, e, em lugar de abraçarem outro modo de vida, seria melhor que voltassem à verdadeira vida apostólica que Deus reservou para estes últimos tempos. Este modo de vida pertence ao quarto e último status e difere fundamentalmente do de São Francisco e São Domingos por ser mais radical quanto à pobreza e por ser mais espiritual do que todos os anteriores, devendo perdurar até o fim do mundo e colher os seus frutos até o dia do Juízo Final. Assim vemos que Dolcino de Novara e seus discípulos adotam uma subdivisão da história partindo do esquema estabelecido por Joaquim de Fiore e os joaquimitas posteriores onde a própria história da Igreja se revela em quatro etapas ou mutationes. Na primeira ela permanece casta e pura sob a perseguição de Constantino. $\mathrm{Na}$ segunda, ela permanece boa, ainda que rica, enquanto o clero e os religiosos seguiam os exemplos do Papa Silvestre, São Bento, São Domingos e São Francisco. No terceiro, que é o contemporâneo de Dolcino, assistimos a uma Igreja em declínio, sendo que este perdurará durante três anos até quando todo o clero e os religiosos forem cruelmente mortos. No quarto período a Igreja tornar-se-á verdadeira "bona et pauper, et persecutiones passa in proprio modo vivendo apostolico reformato". Segundo o simbolismo dos Sete Anjos e as Sete Igrejas do Apocalipse, freqüentemente adotado também por Joaquim, Dolcino considera São Bento como sendo o Anjo de Éfeso e sua igreja como sendo a ordem monástica; do mesmo modo que o Anjo de Pérgamo era o Papa Silvestre cuja
11 De Vita Sancti Benedicti et de officio Divino secundum eius doctrinam, ed. C Baraut, Analecta Sacra Tarraconensia, XXIV, 1951, pp. 42-118.
12 Bartolomeu de Pisa, "De Conformitate Vitae Beat Francisci ad Vitam Domini Francisci ad Vitam Domin Iesu", in Analecta
Franciscana, IV, 1906.
13 Ver a respeito: M. Reeves, The Influence of Prophecy in the Middle Ages, Oxford, 1969, pp. 243-8; N. Falbel, Heresias Medievais, São Paulo, Perspectiva, 1977 . pp. 66-71.


igreja é a ordem dos clérigos; o Anjo de Sardes era São Francisco, com seus Frades Menores; o de Laodicéia, São Domingos com seus Frades Predicantes; o de Esmirna, Frei Gerardo de Parma, fundador da seita de Dolcino e identificado como Gerardo Segarelli; o de Tiatira, como sendo Fra Dolcino e o de Filadelfia como sendo o Papa Angelicus que deverá vir futuramente para governar a Igreja e a humanidade cristã.

Nessa visão da heresia medieval, novamente, São Bento representa um elo importante nas etapas do desenvolvimento espiritual da humanidade e da Igreja até a sua realização final.

Em seu escrito, no Tractatus super Quatuor Evangelia, Joaquim de Fiore inclui São Bento entre os viri spirituals, através dos quais se manifesta o Espírito Santo, e que possuíam o privilégio da graça tal como Moisés e Elias no Velho Testamento e o Apóstolo Paulo no Novo Testamento. E não somente estes, mas, ao lado de São Bento, encontramos também Santo Antônio, um dos patriarcas do monaquismo oriental, expressando-se o nosso abade enfaticamente “... utpote in veteris Moyses et Helias, in novo Paulus, Antonius, Benedictus et ceteri, perfectipatres, filii omnipotentis Dei et reges in Spiritu dicti sunt, secundum quod de talium ordine, qui per successionem perseveraturus est usque in finem seculi..." (14). Assim, a ordo monachorum em Joaquim de Fiore possui uma linha histórica que tem início com as origens remotas do monaquismo através de Santo Antônio, passando por São Bento, e vai atingir a sua plenitude na Idade do Espírito Santo, quando toda a cristandade passará a vivenciá-la.

Em várias passagens, Joaquim de Fiore se mostra atento a essa linha histórica da ordo monachorum que nasceu no útero da Igreja Oriental e foi levada para o deserto (in utero ecclesiae Orientalis inventus est et a spiritu expulsus in desertum) (15), ou, ainda, que

14 Tractatus super Quatuor Evangelia, op. cit, p. 169, 5.

15 Idem, ibidem, pp. 25,2; 33 , 3-5.

16 Idem, ibidem, p. 86,5; p. 182, 19-20; p. 183, 20-1; p. 232, 15-6; p. 238, 11.

17 Conc. lib. II, Tract. 1, cap. 13.

18 Conc. lib.V, cap. 48 e seg. prima ordinis monachorum" e, a contar de seu tempo até a décima sexta geração, quando se dá a "secunda initiatio ordinis monachorum" com São Bento, que, conforme a citação que Joaquim nos traz do Liber Dialogorum de Gregório de Magno, "foi chamado por Deus à ordem monástica”. Após 37 gerações, a partir de Eliseu, continua Joaquim, foi fundada em Molesme a Ordem Cisterciense, assim como na $40^{\mathrm{a}}$ geração foi fundada a Ordem Florense por ele mesmo, e na 42 a geração deverá ter início a "terceira idade", quando os homens viverão sob a perfeição evangélica (tertius status sub evangelica perfectione incipit) (17).

Esse anseio de plenitude e realização da ordo monachorum será expresso por Joaquim em termos elevados ao enaltecer a obra de São Bento através de uma interpretação do sonho de Jacó, em que lembra mais uma vez a divisão trinitária da história ao mesmo tempo que reafirma ser a terceira e última idade o período em que o Espírito Santo se manifestará especialmente na ordem monacal (quia Spiritus sanctus qui operatur specialius in ordine monachorum...):

"vidit autem nocte illa quasi in somnis scalam a terra usque ad celum per quam ascensuri essent humiles corde ipsa est regula monachorum sancti Benedicti, in qua gradus ipsius scale notati sunt, ut appareret quod in tempore ipsius, venerabile illud Iacob mysterium consummationem acciperet, erexit autem Iacob lapidem in titulum, fundens oleum desuper, quia Spiritus Sanctus, qui operatur specialius in ordine monachorum, sicut Filius in ordine clericorum et Pater in ordine Coniugatorum, non operum divisione, sed proprietate mysterii, ipsum Benedictum huius sancte regule institutorem erexit, revera in titulum et in signum, ungens illum oleo sancto suo, de quo unctus est Christus et sancti apostoli: ut esset ex eo tempore pater et duxinnumerabiliummonachorum et esset congregatio eius domus Dei et regula eius portaceli, eo quod per eandem portam multe caterve hominum rapiantur ad Deum" (18). 